Marquette University

e-Publications@Marquette

Speech Pathology and Audiology Faculty Research

and Publications

Speech Pathology and Audiology, Department of

$11-1-2013$

\title{
Speaking Rate Effects on Locus Equation Slope
}

Jeffrey J. Berry

Marquette University, jeffrey.berry@marquette.edu

Gary Weismer

University of Wisconsin - Madison

Accepted version. Journal of Phonetics, Vol. 41, No. 6 (November 2013): 468-478. DOI. (C) 2013

Elsevier. Used with permission. 


\title{
Speaking Rate Effects On Locus Equation Slope
}

\author{
Jeff Berry \\ Department of Speech Pathology and Audiology \\ Marquette University \\ Milwaukee, WI \\ Gary Weismer \\ Department of Communication Sciences \& Disorders \\ University of Wisconsin-Madison \\ Madison, WI
}

\begin{abstract}
A locus equation describes a 1st order regression fit to a scatter of vowel steady-state frequency values predicting vowel onset frequency values. Locus equation coefficients are often interpreted as indices of coarticulation. Speaking rate variations with a constant consonant-vowel form are thought to induce changes in the degree of coarticulation. In the current work, the hypothesis that locus slope is a transparent index of coarticulation is examined through the analysis of acoustic samples of large-scale, nearly continuous variations in speaking rate. Following the methodological conventions for locus equation derivation, data pooled across ten vowels yield locus equation slopes that are mostly consistent with the hypothesis that locus equations vary systematically with coarticulation. Comparable analyses between different four-vowel pools reveal variations in the locus slope range and changes in locus slope sensitivity to rate change. Analyses across rate but within vowels are substantially less consistent with the locus hypothesis. Taken together, these findings suggest that the practice of vowel pooling exerts a non-negligible influence on locus outcomes. Results are discussed
\end{abstract}


NOT THE PUBLISHED VERSION; this is the author's final, peer-reviewed manuscript. The published version may be accessed by following the link in the citation at the bottom of the page.

within the context of articulatory accounts of locus equations and the effects of speaking rate change.

\section{Introduction}

A locus equation describes a 1st order regression fit to a scatter of vowel steady-state frequency values predicting vowel onset frequency values (Lindblom, 1963). Conventionally, these discrete measures are taken from the second formant (F2). The data necessary to derive a locus equation include samples of a particular consonant (often a stop) combined with "a range of vowel contexts" for a specific speaker (Sussman, Fruchter, Hilbert, \& Sirosh, 1998, p. 246).

Presumably the precise number and specific vowel contexts have little implication on locus regression lines. One oft-defended implication of these regression lines is that the coefficients offer an index of coarticulation (Krull, 1988). Articulatory accounts of locus equations are equivocal regarding this perspective (Iskarous, Fowler, \& Whalen, 2010; Löfqvist, 1999; Tabain, 2000, 2002). Studies using articulatory synthesis models of locus equations present a straightforward relation between coarticulation and locus line variation (Chennoukh, Carré, \& Lindblom, 1997; Lindblom \& Sussman, 2004, 2012). However, speaking rate-induced coarticulatory variation appears to be quite idiosyncratic, and not governed by simple articulatory-acoustic relationships (Berry, 2011). Thus, the systematic study of rate-induced coarticulatory variation on the locus line is important for evaluating the notion that locus equations provide a transparent method for measuring coarticulation.

Locus-related effects of speaking rate variation have been studied previously. Agwuele, Sussman, \& Lindblom (2008) studied variation across three nominal rates (habitual, fast, fastest) in 10 vowel contexts (per consonant). The design of the experiment generated ten tokens for each rate (per consonant). This sampling of the rate continuum is probably inadequate for the analysis of locus equation slope as a function of rate variation. In the current work, we obtained acoustic samples of large-scale, nearly continuous variations in speaking rate to examine rate effects on locus slope. Speaking rate variation with a constant $\mathrm{CV}$ form induces changes in the overlap of adjacent articulatory gestures, and hence in the degree of coarticulation, sometimes to nearly the same degree as that induced

Journal of Phonetics, Vol 41, No. 6 (November 2013): pg. 468-478. DOI. This article is (C) Elsevier and permission has been granted for this version to appear in e-Publications@Marquette. Elsevier does not grant permission for this article to be further copied/distributed or hosted elsewhere without the express permission from Elsevier. 
by pairing different vowels with the same stop consonant (see, for example, Byrd \& Tan, 1996; Tjaden \& Weismer, 1998; Weismer \& Berry, 2003). The principal aim of the current work is to evaluate the effects of rate variation on the locus line as a means to examine the notion that locus equations offer a transparent index of coarticulation.

\subsection{Articulatory studies of locus equations}

Löfqvist (1999) examined the relationship between locus slope and three articulatory-kinematic measures of coarticulation across stop-place contrasts produced by four speakers, but found little evidence relating the articulatory level of analysis to locus slope. Tabain $(2000,2002)$ analyzed electropalatographic data and found support for the notion that locus slope reflects coarticulation only for voiced (lingual) stop and nasal consonants, with little evidence supporting extension to voiceless stops and fricatives. Iskarous et al. (2010) analyzed articulatory-kinematic positions from data obtained from a single talker for various consonant contexts across six vowels. They also analyzed eight vowels per consonant context from 38 talkers from the X-ray Microbeam Database. For both data sets, Iskarous et al. (2010) demonstrated linearity in the relation between the horizontal positions of a tongue blade marker at the vowel midpoint relative to the position at consonant closure. Because this articulatory result mimics the linearity seen in acoustically-defined first-order locus equations, the authors suggest that locus slope is a transparent reflection of articulator position and coarticulation.

Potential differences in the outcomes of these studies may reflect methodological issues. For example, Löfqvist (1999) indexed the acoustic and articulatory data independently, while Iskarous et al. (2010) indexed the kinematic measurements based on the time of occurrence of the acoustic measures used in the locus equations. Moreover, these two studies differ in the extent to which the kinematic measures reflect time-varying changes in articulation. Löfqvist (1999) used kinematic measures reflecting characteristics of the time-varying articulatory transitions defined along both the horizontal and vertical movement dimensions, while Iskarous et al. (2010) used discrete-time position measures defined along a single movement dimension (horizontal position). The time-varying approach arguably reflects a

Journal of Phonetics, Vol 41, No. 6 (November 2013): pg. 468-478. DOI. This article is (C) Elsevier and permission has been granted for this version to appear in e-Publications@Marquette. Elsevier does not grant permission for this article to be further copied/distributed or hosted elsewhere without the express permission from Elsevier. 
NOT THE PUBLISHED VERSION; this is the author's final, peer-reviewed manuscript. The published version may be accessed by following the link in the citation at the bottom of the page.

conceptually clearer parameterization of the kinematic analysis of coarticulation and perhaps a more robust appraisal of the articulatoryacoustic relations.

\subsection{Articulatory synthesis modeling of locus equations}

Despite the equivocal results obtained in articulatory studies of locus equations, a bulk of data consistent with the notion that locus slope is a transparent index of coarticulation have been derived from articulatory synthesis models (Chennoukh et al., 1997; Lindblom \& Sussman, 2004, 2012). Lindblom and Sussman (2012) provide the most recent and comprehensive review of modeling evidence. Clearly, articulatory synthesis modeling suggests a direct relationship between articulatory manifestations of coarticulation and locus equation slope. A key consideration regarding such efforts is that these models require specification of the articulatory manifestations of coarticulation as inputs. Löfqvist (1999) suggests that modeling work may artificially simplify the articulatory manifestations of coarticulation. His concerns are paralleled in the literature on speaking rate-induced coarticulatory variation, where articulatory changes appear to be quite complex and idiosyncratic (Berry, 2011).

\subsection{Acoustic studies of speaking rate}

Acoustic studies of speaking rate change have reported numerous speaker and context related effects on formant frequencies (Agwuele et al., 2008; Fourakis, 1991; Gay, 1968, 1978; Hertrich \& Ackermann, 1995; Lindblom, 1963; Pitermann, 2000; Rosen et al., 2011; Tjaden \& Weismer, 1998; Weismer \& Berry, 2003). Because of the perceptual relevance and greater context sensitivity of F2 compared to F1 and F3 (Stevens \& House, 1963), rate effects on F2 have received the most attention. The most commonly reported finding of acoustic studies reflects "undershoot" of the formant target values with increasing rate (cf., Lindblom, 1963), though this result is not pervasive across speakers and (vowel) contexts (Weismer \& Berry, 2003).

Consideration of acoustic effects cannot be limited to discretetime measures of F2 variation. For example, Weismer and Berry

Journal of Phonetics, Vol 41, No. 6 (November 2013): pg. 468-478. DOI. This article is (C) Elsevier and permission has been granted for this version to appear in e-Publications@Marquette. Elsevier does not grant permission for this article to be further copied/distributed or hosted elsewhere without the express permission from Elsevier. 
(2003) analyzed rate-induced changes in both discrete-time acoustic parameters (e.g., F2 onset and target values) as well as time-varying F2 trajectory shapes. Based on six speakers, who produced wide ranges of speaking rates, they found not only pervasive speaker and (vowel) context-conditioned differences in the rate-induced effects on discrete-time parameters, but also individual differences in rateinduced changes in formant transition shapes.

The notion that rate-induced coarticulatory changes may be complex and idiosyncratic poses a challenge to the idea that locus equations offer a transparent index of coarticulation. Since the literature examining the articulatory manifestations of rate-induced coarticulatory variation is large, compared to the paucity of articulatory studies of locus equations, detailing the complexity of rate-induced coarticulary variation provides justification that speaking rate variation offers a critical challenge to locus equation theory and may offer insights useful for assessing data reflecting rate-induced variation in the locus line.

\subsection{Articulatory studies of speaking rate}

The effects of speaking rate variation appear to have particularly complex influences on articulation. Kinematic studies of speaking rate change have examined both discrete and time-varying measures of articulation. In summarizing this literature, four primary measures of interest can be identified: (1) articulatory velocity (speed); (2) movement extent (distance); (3) relative timing (phasing); and (4) velocity profiles. Summarizing the kinematic effects of rate-induced coarticulatory change, Berry (2011) emphasizes the apparent wide idiosyncracy of rate-induced kinematic modifications, with the additional observation that rate transformations may differ between articulators within speaker.

\subsubsection{Articulatory velocity}

Several studies have reported increased peak velocities with increased speaking rate (Abbs, 1973; Adams, Weismer, \& Kent, 1993; Flege, 1988; Gay \& Hirose, 1973; Hertrich \& Ackermann, 2000; Kuehn \& Moll, 1976; Ostry \& Munhall, 1985; Shaiman, 2001, 2002), but results have not always been consistent across articulators (Hertrich \&

Journal of Phonetics, Vol 41, No. 6 (November 2013): pg. 468-478. DOI. This article is (C) Elsevier and permission has been granted for this version to appear in e-Publications@Marquette. Elsevier does not grant permission for this article to be further copied/distributed or hosted elsewhere without the express permission from Elsevier. 
Ackermann, 2000; McClean, 2000; Tasko \& McClean, 2004). Some studies have found little or no evidence of changes in articulator velocities as a function of rate (Kent \& Moll, 1972; Benguerel \& Cowan, 1974), and individual differences with regard to the occurrence of velocity changes (Flege, 1988; Goozee, Stephenson, Murdoch, Darnell, \& Lapointe, 2005; Kuehn \& Moll, 1976; Ostry \& Munhall, 1985), with some talkers showing reduced articulator velocities at faster speaking rates (McClean, 2000; Tasko \& McClean, 2004) or increased articulator velocities at slower rates (Kent $\&$ Moll, 1972). Thus, despite the fact that a direct relationship between articulator movement velocity and speaking rate seems like an intuitive solution to the problem of rate transformation, kinematic data do not universally support such an explanation.

\subsubsection{Articulatory extent}

Articulatory movement extent (distance) seems like the most obvious kinematic expression of acoustic undershoot, and reported decreases in articulator movement extent with increases in speaking rate are common (Byrd \& Tan, 1996; Flege, 1988; Gay, Ushijima, Hirose, \& Cooper, 1974; Kent \& Moll, 1972; Ostry \& Munhall, 1985; Shaiman, 2001). Most kinematic studies have examined this variable with respect to the relationship with movement velocity, with several studies reporting a direct relationship between the two variables (Abbs, 1973; Hertrich \& Ackermann, 2000; Kent \& Moll, 1972; Kuehn \& Moll, 1976; Ostry, Keller, \& Parush, 1983; Shaiman, 2001). This finding is not universal across talkers or studies (e.g., Abbs, 1973; Benguerel \& Cowan, 1974; Flege, 1988; Gay, 1981; Kent \& Moll, 1972; Kuehn \& Moll, 1976).

The "move farther, move faster" relation is logically at odds with the most predictable of the rate-induced effects, as it is inconsistent with the possible combination of undershoot and increasing articulatory speeds for faster rates and slower movements with longer extents for slower speech. Thus, across speaking rates, we might expect a weakening of the relationship between speed and distance to be more likely than maintenance of a strong, direct relationship (McClean \& Tasko, 2003). Slow speech, in particular, may require alternate control strategies that change the relations among segment duration, movement extent, and velocity (Berry, 2011; Perkell,

Journal of Phonetics, Vol 41, No. 6 (November 2013): pg. 468-478. DOI. This article is (C) Elsevier and permission has been granted for this version to appear in e-Publications@Marquette. Elsevier does not grant permission for this article to be further copied/distributed or hosted elsewhere without the express permission from Elsevier. 
Zandipour, Matthies, \& Lane, 2002). These relations have been proposed to underlie a linear second order (mass-spring) control model for rate that uses the ratio of maximum velocity to movement extent as a stiffness parameter (Kelso, Vatikiotis-Bateson, Saltzman, \& Kay, 1985; Ostry \& Munhall, 1985). Fuchs, Perrier, and Hartinger (2011) use kinematic data to argue that such a model assumes oversimplified representations of damping and stiffness (that are not really invariant over time within segment) and is limited in the context of kinematic data, where knowledge of force parameters is lacking.

\subsubsection{Relative articulatory timing (phasing)}

Measures of relative temporal overlap (phase) between articulatory movements are the third domain within which the effects of speaking rate on speech-kinematic behavior have been studied. Rate-induced effects on temporal overlap appear to be no more universal than other kinematic variables. Within and across studies, there are reports that increasing speaking rate results in (1) increased overlap; (2) no change in overlap; or (3) decreased overlap (e.g., Abbs, 1973; Boyce, Krakow, Bell-Berti, \& Gelfer, 1990; Byrd \& Tan, 1996; Engstrand, 1988; Shaiman, 2001, 2002; Shaiman, Adams, \& Kimelman, 1995). Berry (2011) presents articulatory synthesis data that suggest that simplified representations of coarticulation (e.g., manipulating only articulatory phasing) that are typical in articulatory synthesis modeling can produce unrealistic time-varying acoustic patterns that are eliminated by modeling coarticulation through multiple, simultaneous kinematic transformations (i.e., scaling articulatory movement velocity, extent, and phasing). Nonetheless, the concept of phase independently assumes a critical role in certain theoretical frameworks for speech motor control (Kelso, Saltzman, \& Tuller, 1986; Saltzman \& Byrd, 2000).

\subsection{Coarticulation: the intersection of speaking rate and locus equations}

Speaking rate change is a common means for eliciting coarticulatory variation. Locus equations are purported to be an index of coarticulation. These simple statements suggest a practical point of intersection between an experimental manipulation and a widely-

Journal of Phonetics, Vol 41, No. 6 (November 2013): pg. 468-478. DOI. This article is (C Elsevier and permission has been granted for this version to appear in e-Publications@Marquette. Elsevier does not grant permission for this article to be further copied/distributed or hosted elsewhere without the express permission from Elsevier. 
embraced analytic method. Moreover, theoretical accounts of both rate-induced coarticulatory variation and locus equation accounts of coarticulation share some common ground. In particular, the theoretical significance of velocity profiles and the insights of Lindblom's (1990) hyper-to-hypoarticulation theory provide theoretical points of intersection between speaking rate and locus equations.

\subsubsection{Velocity profiles}

In addition to discrete-time parameterizations of articulatory movement, more complete (segmental) histories of articulator velocity are also thought to provide important evidence regarding the nature of rate transformation (Adams et al., 1993; Munhall, Ostry, \& Parush, 1985; Ostry, Cooke, \& Munhall, 1987; Shaiman et al., 1997). Velocity profiles have been attributed great significance in some control models of human movement (Plamondon, 1995) and have been purported to reflect upon the relationship between speech and non-speech movement characteristics (Munhall et al., 1985; Ostry et al., 1987). While much of the literature analyzing velocity profiles for speech suggests that movements maintain a universal form at this level of analysis, Adams et al. (1993) report that talkers tend to exhibit singlepeaked, symmetrical velocity profiles at habitual and fast speaking rates, but multi-peaked, asymmetrical velocity profiles at slower speaker rates. These findings may reflect changes in the sensorimotor control strategies across the speaking rate continuum, with preprogrammed, feedforward type controls for habitual and faster movements, and feedback type control for slower rates (Adams et al., 1993; Berry, 2011).

The form of velocity profiles may be critical to the linearity of locus equations. Lindblom and Sussman (2012) propose that locus equation linearity is critically dependent on the uniformity of velocity profiles across speech movements. A lack of uniformity would result in varying time constants (a lack of proportional timing equivalence) across different (vowel) F2 transitions causing non-uniform variation in locus slope, based on differences in the locus-target distance for different vowels. Consequently, asymmetrical, multi-peaked velocity profiles that may be particularly likely in extreme slow speech could compromise locus line linearity. This is an important consideration with respect to potential clinical applications of locus equations, since

Journal of Phonetics, Vol 41, No. 6 (November 2013): pg. 468-478. DOI. This article is (C) Elsevier and permission has been granted for this version to appear in e-Publications@Marquette. Elsevier does not grant permission for this article to be further copied/distributed or hosted elsewhere without the express permission from Elsevier. 
individuals with motor speech disorders often produce slow rates of speech (Niimi, 2001; Nishio \& Niimi, 2006). Also, since intrinsic vowel durations and rate effects on duration are not uniform across vowels or speakers (Crystal \& House, 1982, 1988a, 1988b; Hillenbrand, Getty, Clark, \& Wheeler, 1995; Tsao \& Weismer, 1997; Tsao, Weismer, \& Iqbal, 2006a, 2006b), it is important to determine if certain vowels or vowel combinations are differentially sensitive to rate-induced locus slope variation.

\subsubsection{Hyper-to-hypoarticulation}

Gay (1981) argues that speaking rate transformations are multidimensional and nonlinear. The particular magnitude and constellation of effects on articulatory parameters will vary by speaker, context, and articulator. Lindblom's (1990) concept of the hyper-tohypoarticulation dimension adds further complexity to the characterization of rate transformation and the utility of locus equations as indices of coarticulation, since talkers can control segment duration and hyper-hypoarticulation separately (Moon \& Lindblom, 1994), and the effects of increasing rate and increasing emphasis both manifest along the same dimensions (duration and elaboration/reduction) but in opposite directions (Agwuele et al., 2008; Lindblom, Agwuele, Sussman, \& Cortes, 2007; Lindblom, Sussman, \& Agwuele, 2009). A talker can presumably accomplish rate change at any location along the hyper-hypoarticulation continuum, further reducing the predictability of the effect of a talker's rate modification and challenging the capacity of locus equations to characterize coarticulatory variation.

\subsection{Cross-vowel pooling \& locus equation theory}

Individual vowel contexts have unique coarticulatory demands with varying intrinsic segment durations and varying propensities for compression or expansion in response to rate change. Consequently, it seems problematic to pool data across vowel contexts if the aim is to characterize rate-induced coarticulatory variation. Nonetheless, the locus equation method is premised on the practice of cross-vowel pooling. Thus, it is reasonable to ask if and why acoustic data conform to the hypothesis that locus equations index rate-induced

Journal of Phonetics, Vol 41, No. 6 (November 2013): pg. 468-478. DOI. This article is (C) Elsevier and permission has been granted for this version to appear in e-Publications@Marquette. Elsevier does not grant permission for this article to be further copied/distributed or hosted elsewhere without the express permission from Elsevier. 
coarticulatory variation. Toward this end, a more detailed appraisal of speaking rate effects on locus slope is needed. Moreover, an exploration of the impact of cross-vowel pooling of locus data may be useful since rate transformations reflect a complex, idiosyncratic interplay among a variety of articulatory parameters.

Over the past decade, the concept of locus equations has been instrumental in stimulating discussions about the relations between speech production and perception. Not limited to the domain of mature, typically functioning speakers, locus equation data have also informed perspectives on speech development and disorders (Chang, Ohde, \& Conture, 2002; Gibson \& Ohde, 2007; Morrison, 2008, 2012; Sussman et al.,1998; Sussman, Hoemeke, \& McCaffrey, 1992; Sussman, Minifie, Buder, Stoel-Gammon, \& Smith, 1996). Locus equations suggest an extremely manageable solution to the problem of articulatory-acoustic invariance. Requiring only two samples of F2 along the course of each instance of a consonant-vowel (CV) form, the locus approach implies a nearly equivalent dimensionality between segments and acoustics (we say "nearly" because, as noted by Mattingly (1998), the procedure for deriving locus equations cannot be obviously generalized to other segments and word forms).

Invariance, however, cannot be derived from simply connecting the endpoints of single transitions (Fant, 1973). The locus concept creatively derives invariance as a consequence of variability. Thus, an ensemble of transitions is required to expose the invariant constraints on articulation. For a single consonant, a satisfactory ensemble of data includes multiple vowel contexts. For a particular consonant (in CV form), the validity of cross-vowel data pooling could be justified by accepting the notion of uniform coarticulatory resistance (Fowler, 1994). From this perspective, a particular consonant carries an invariant degree of resistance to the coarticulatory influences of different vowels. As Fowler (1998, p. 265) explains: "vowels all use the tongue body, so their interference with a given consonant should be approximately the same." She makes this argument to provide an articulatory explanation for the locus line and, ostensibly, eliminate the need for a perceptual basis for the phenomenon. Sussman et al. (1998, p. 293) reject this notion, citing "operator-based timing decisions" as the primary determinant of the locus line. The speaker, then, and their coarticulatory choices determine the characteristics of

Journal of Phonetics, Vol 41, No. 6 (November 2013): pg. 468-478. DOI. This article is (C) Elsevier and permission has been granted for this version to appear in e-Publications@Marquette. Elsevier does not grant permission for this article to be further copied/distributed or hosted elsewhere without the express permission from Elsevier. 
the locus line. In more recent formulations (Lindblom \& Sussman, 2004, 2012), the articulatory-acoustic mapping of the human vocal tract, apparent constancy of the spatio-temporal form of articulatory movements, and differential biomechanical constraints across the regions of the tongue (see also Iskarous et al., 2010) are thought to make non-negligible contributions to the characteristics of the locus equation. With such adjunct hypotheses, a less stringent version of the locus theory emerges. The determination of the locus line is, at least in part, a natural by-product of the characteristics of human vocal tracts and human motor behavior.

We hypothesize that some of the apparent predictability of locus equation slope variation derives directly from the method of crossvowel pooling through which locus slope values are determined. A detailed appraisal of the influence of speaking rate on locus equation slope provides a context for evaluating this hypothesis, since coarticulation can be influenced by several different things, including the particular combination of consonant and vowel (indeed, the whole basis of slope varying by place) and speaking rate. The source of coarticulatory influence is a poignant consideration, since much remains to be determined about differences in locus line variation resulting from differences in place of articulation versus speaking rate change. The challenge of understanding rate-induced coarticulatory variability is particularly important because of the well-documented idiosyncracy of rate effects (Berry, 2011) and the need to develop models of coarticulation that can replicate individual variability using manipulations of speaker-general system variables (Simko \& Cummins, 2010).

\subsection{Specific aim and hypotheses}

The aim of the current work is to evaluate the effects of rate variation on the locus line and appraise the impact of cross-vowel data pooling in order to examine the notion that locus equations offer a transparent index of coarticulation. Three hypotheses are examined in the current study: (1) a reduction in gesture overlap with decreasing speaking rate (Munhall \& Löfqvist, 1992; Weismer \& Berry, 2003) should be manifest acoustically as a reduction in locus slope if the slope of a locus equation is a transparent index of coarticulation;

Journal of Phonetics, Vol 41, No. 6 (November 2013): pg. 468-478. DOI. This article is (C Elsevier and permission has been granted for this version to appear in e-Publications@Marquette. Elsevier does not grant permission for this article to be further copied/distributed or hosted elsewhere without the express permission from Elsevier. 
comparable analyses across different groupings of pooled vowels should reflect similar outcomes if cross-vowel pooling does not provide a critical influence on locus slope determination; and (3) within vowel analyses may reveal speaker-general differences in the rate-induced coarticulatory transformations between vowels if rate-induced locus slope variation is affected by different vowel groupings.

\section{Material and methods}

\subsection{Speakers and sample}

Acoustic data were obtained from two adult males (JB and GW, the authors) and two adult females (PL and RM, graduate students). It should be noted that the relatively dense sampling of data across rate and vowel requires a substantial amount of data per participant. Moreover, four speakers is a sufficient number to appraise the influence of vowel pooling across rate since each participant effectively serves as his/her own control across conditions. Informed consent was obtained from all subjects, and all procedures were approved by the Human Subjects Committee at the University of Wisconsin-Madison and the Marquette University Institutional Review Board. Speakers PL and RM both have dialects typical of the Northwestern suburbs of Chicago, Illinois. Speaker JB has a dialect typical of Wisconsin's Fox River Valley, whereas GW's dialect is a mix of that heard in Southcentral Wisconsin and Southeastern Pennsylvania. Each of the speakers completed a graded speaking rate task for the carrier phrase "Say again." In short, the carrier phrase and target word are repeated in sequences of ascending or descending speaking rate (Weismer \& Berry, 2003). The resulting target-word vowel durations reveal a wide and nearly continuous range of speaking rates. Assuming rate change induces changes in coarticulation, as reviewed in Section 1, the procedure evokes a wide variety of degree of coarticulation between the consonant and vowel. Keeping with the need to sample multiple vowel contexts, each speaker produced 80 repetitions for each of ten target words: beat, bit, bait, bet, bat, but, boot, boat, bought, bot. The initial consonant [b] was chosen to maximize articulatory independence between consonant and following vowel and hence the potential for coarticulatory variation by allowing the tongue to be free to assume the vowel position during stop closure

Journal of Phonetics, Vol 41, No. 6 (November 2013): pg. 468-478. DOI. This article is (C) Elsevier and permission has been granted for this version to appear in e-Publications@Marquette. Elsevier does not grant permission for this article to be further copied/distributed or hosted elsewhere without the express permission from Elsevier. 
(Lindblom \& Sussman, 2012). The 800 tokens analyzed per speaker for this consonant context allowed a sufficiently dense sample to assess rate-induced effects on locus slope both across and within vowel. The total volume of data analyzed (3200 tokens) for this study is nearly twice the total volume of data presented in the speaking rate study of Agwuele et al. (2008).

All utterances were recorded in a sound attenuated booth using a Shure SM-58 dynamic microphone and digitized direct-to-disk on a laboratory computer using the Soundforge audio software with Sound Blaster $16 \mathrm{~A} / \mathrm{D}$ converter. Data were digitized at a $22.05 \mathrm{kHz}$ sampling rate with 16-bit quantization. Temporal and spectral measurements of the data were obtained using the TF32 speech analysis software (Milenkovic, 1998).

\subsection{Data analysis and post-processing}

Viewing an approximate $1 \mathrm{~s}$ window of speech centered upon a target word, cursors were placed at the first and last regular voicing striations associated with the vowel. The extent of the interval between these cursor positions was identified as the target vowel duration. This measure was used as an index of speaking rate (Weismer \& Berry, 2003). The temporal location of the initial cursor position for a target vowel specified the time of occurrence of the F2 onset value. The time of occurrence of the F2 target value was identified as one-half the temporal distance from the beginning to the ending cursor position for each target vowel. This fixed measurement rule for the identification of the F2 target value was adopted even though Sussman et al. (1998, p. 248) used a slightly more flexible approach based on the notion that "[t]he exact time at which F2 vowel frequencies are sampled does not seem to be too important." Moreover, we decided to take the F2 onset at the first glottal pulse, rather than in the immediate vicinity of the burst (see Modaressi, Sussman, Lindblom, \& Burlingame, 2005) because the latter location would have been associated with missing data points (due to weak or absent bursts) and, in our opinion, relatively poor reliability.

Spectral measurements of F2 were obtained using criteria outlined below in conjunction with an LPC-based trace of the F2 history throughout each target word. Formant tracks were determined pitch-

Journal of Phonetics, Vol 41, No. 6 (November 2013): pg. 468-478. DOI. This article is (C Elsevier and permission has been granted for this version to appear in e-Publications@Marquette. Elsevier does not grant permission for this article to be further copied/distributed or hosted elsewhere without the express permission from Elsevier. 
synchronously using a 24-coefficient LPC algorithm. Tracks were subsequently hand-smoothed with linear interpolation to eliminate visually unreasonable LPC estimates. With reference to the temporal locations identified during the indexing process described above, values of F2 onset and F2 target were obtained for each replicate of each target word. Pooled across vowel contexts, linear regression fits of F2 target predicting F2 onset determined the conventionally defined locus line.

\subsection{Vowel pooling and rate categories}

In addition to the analysis of locus line slope variation calculated from data pooled across all vowel contexts, five different vowel pooling conditions were compared: (1) point vowels $(/ \mathrm{i} /, / \Re /, / \mathrm{d} /, / \mathrm{u} /)$; (2) front vowels $(/ \mathrm{i} /, / \mathrm{e} /, / \varepsilon /, / æ /) ; 3)$ back vowels $(/ \mathrm{d} /, / \mathrm{J} /, / \mathrm{o} /, / \mathrm{u} /) ; 4)$ low vowels $(/ \varepsilon /, / æ /, / \mathrm{d} /, / \mathrm{J})$; and (5) high vowels $(/ \mathrm{i} /, / \mathrm{e} /, / \mathrm{o} /$, $/ \mathrm{u} /)$. The logic of these various groupings was governed by basic phonetic dimensions of vowel production, that correspond roughly with different speaker-general combinations of F1 \& F2 sensitivities to articulatory change. It was presumed that any differences in rateinduced locus-slope variation between groups might be useful in generating hypotheses regarding articulatory-acoustic dimensions that influenced locus sensitivity to coarticulatory change. Given four vowels each, the comparable pooling conditions were comprised of 320 replicates per speaker that were then divided into subject-specific quartiles of vowel duration to reflect categorically-distinct speaking rates. Within-subject quartiles of vowel duration provided an operational means for defining speaking rate categories. These measures are affected somewhat by vowel-intrinsic durational differences and talker idiosyncracies, but the method provides a reasonable division of speech samples into categorically distinct speaking rates (Weismer \& Berry, 2003).

\section{Results}

\subsection{Data distributions}

Weismer and Berry (2003) found that the graded rate task evokes different ranges of durational change for each speaker. This

Journal of Phonetics, Vol 41, No. 6 (November 2013): pg. 468-478. DOI. This article is @ Elsevier and permission has been granted for this version to appear in e-Publications@Marquette. Elsevier does not grant permission for this article to be further copied/distributed or hosted elsewhere without the express permission from Elsevier. 
outcome parallels the cross-speaker differences reported for read, connected speech (Crystal \& House, 1988b). Consistent with previous findings, the current speakers exhibited distinct ranges of variation. Fig. 1 shows raw data characterizing the variations in durational and spectral measures for target words that include the point vowels for each speaker. Vowel contexts are coded by color with F2 onset and target values for each of the four vowels indicated by circles and triangles, respectively. Quadratic trend lines are included to highlight the relationships among individual spectral parameters and vowel duration. Trend lines for all F2 targets are in black and trend lines for F2 onsets are shown in the color corresponding with each vowel context.

Fig. 1
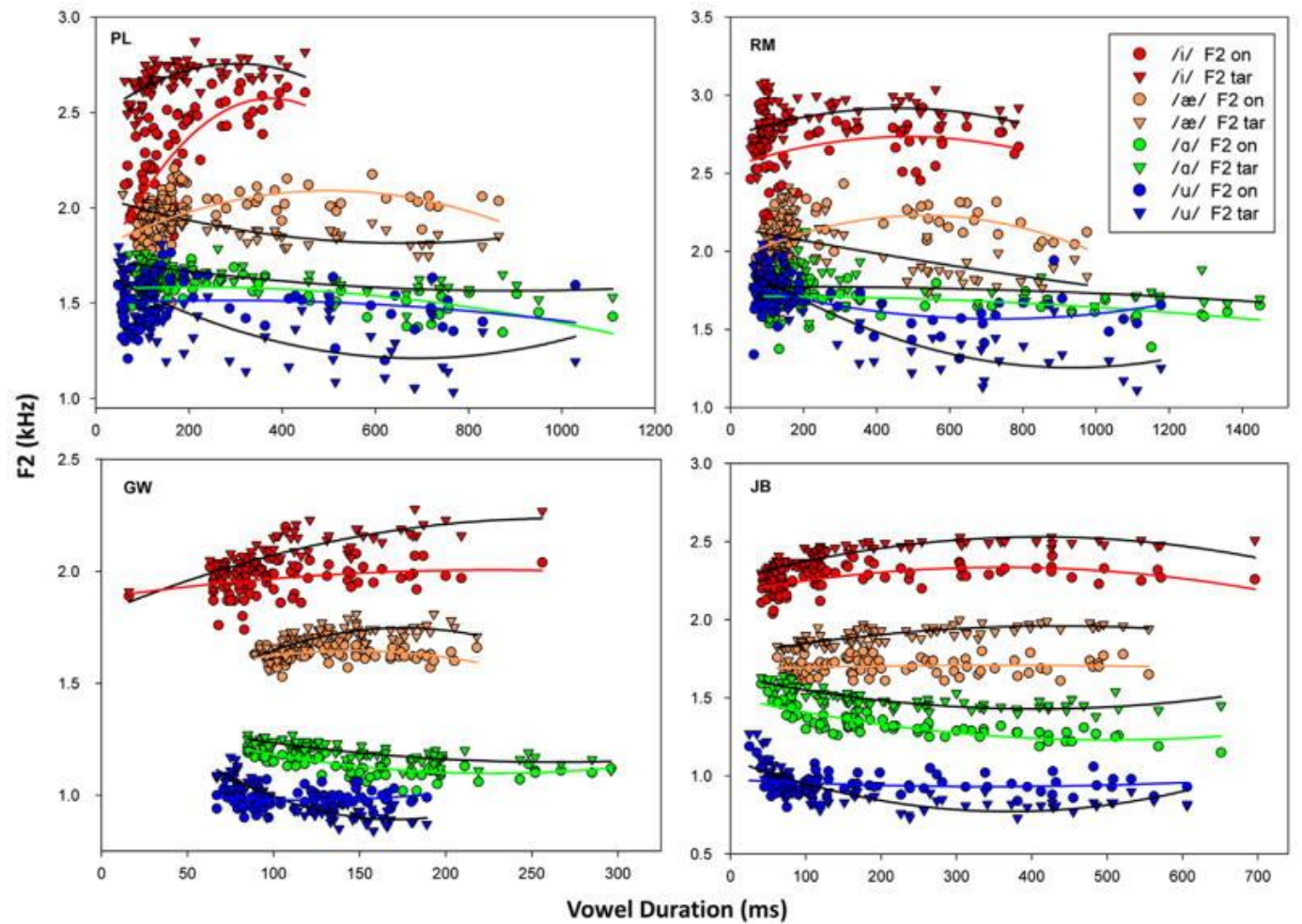

F2 onset and target variation across vowel durations for the point vowels of each participant. Black lines reflect F2 target trends and colored lines show F2 onset trends by vowel.

Consistent with prior findings (Weismer \& Berry, 2003), the graded rate task evokes distributions that tend to be heavily skewed toward shorter vowel durations. For the most part, all speakers show

Journal of Phonetics, Vol 41, No. 6 (November 2013): pg. 468-478. DOI. This article is (C) Elsevier and permission has been granted for this version to appear in e-Publications@Marquette. Elsevier does not grant permission for this article to be further copied/distributed or hosted elsewhere without the express permission from Elsevier. 
customary patterns of intrinsic vowel duration (Crystal \& House, $1988 b)$, despite their distinct ranges of rate change. The range of durational variation varies substantially between speakers and vowels. Outlying vowel durations are typically twice as long for speaker JB compared with GW, and often twice as long for both female speakers ( $\mathrm{PL}$ and $\mathrm{RM}$ ) compared to $\mathrm{JB}$, though vowel-specific differences are quite apparent. For example, PL's range of durational variation for /i/ is only half the range of JB's.

Duration induced variation in individual spectral measures is also consistent with prior results (Weismer \& Berry, 2003). There is some overlap of values between adjacent vowels, yet both F2 onset and F2 target appear to follow trends according to vowel identity. Spectral variation for both F2 onset and F2 target appears to be differently affected by durational change in vowel and speaker-specific ways. For example, while GW shows a trend toward F2 target undershoot with increasing rate for /i/, PL shows a trend toward F2 onset undershoot. In contrast, RM and JB both show relative constancy of the distance between F2 onset and target across rates for the vowel /i/. For the /a/ context, all speakers tend to show relative constancy in the distance between the onset and target distance across rates.

\subsection{Locus line by rate and speaker, across vowel context}

Speaking rate categories were defined operationally by dividing the data into subsets based on speaker-specific quartiles of vowel duration. The middle-half of each distribution is consistent with expected natural ranges of variation (100-200 ms) (Crystal \& House, 1988b). Middle quartiles, then, are reasonably regarded as conversational "fast" and "slow" speech. The 1st and 4th quartiles of each distribution are reasonably regarded as "extremely fast" and "extremely slow" speech, respectively. The pertinent question of interest is: Does the slope of the locus line reduce as speech rate slows? To be consistent with the notion that the slope of the locus line is an index of coarticulation, we would expect locus slope to decrease in the following pattern by quartile: 1 st $>2$ nd $>3$ rd $>4$ th.

Journal of Phonetics, Vol 41, No. 6 (November 2013): pg. 468-478. DOI. This article is (C) Elsevier and permission has been granted for this version to appear in e-Publications@Marquette. Elsevier does not grant permission for this article to be further copied/distributed or hosted elsewhere without the express permission from Elsevier 
Fig. 2 shows data points and locus lines across all vowel contexts and rates for each speaker. Following convention (Sussman et al., 1998), scatters show F2 target values predicting F2 onset. Extremely fast and fast subsets of data are indicated by upward pointing triangles colored red and green, respectively. Locus lines for extremely fast and fast data are indicated by red and green lines comprised of short and medium length dashes, respectively. Slow and extremely slow subsets of data are indicated by downward pointing triangles colored blue and violet, respectively. Locus lines for slow and extremely slow are indicated by blue and violet lines comprised of long length or no dashes (solid), respectively. According to locus theory, then, the slope of the locus lines should vary in the following pattern: red $>$ green $>$ blue $>$ violet (by color) and short-dash $>$ medium dash $>$ long dash $>$ no dash (by line type). This outcome is obtained for each speaker except PL, whose slope changes do not seem to follow a pattern across rates. Moreover, based on the values for the slopes shown in the locus equations for each speaker and quartile, RM's Q3 and Q4 slopes do not differ. Although y-intercept values are not shown in these graphs, the $y$-intercept values are shown in the locus equation obtained for each speaker and quartile. $Y$-intercept values tend to increase as rate decreases for all speakers except PL.

Fig. 2

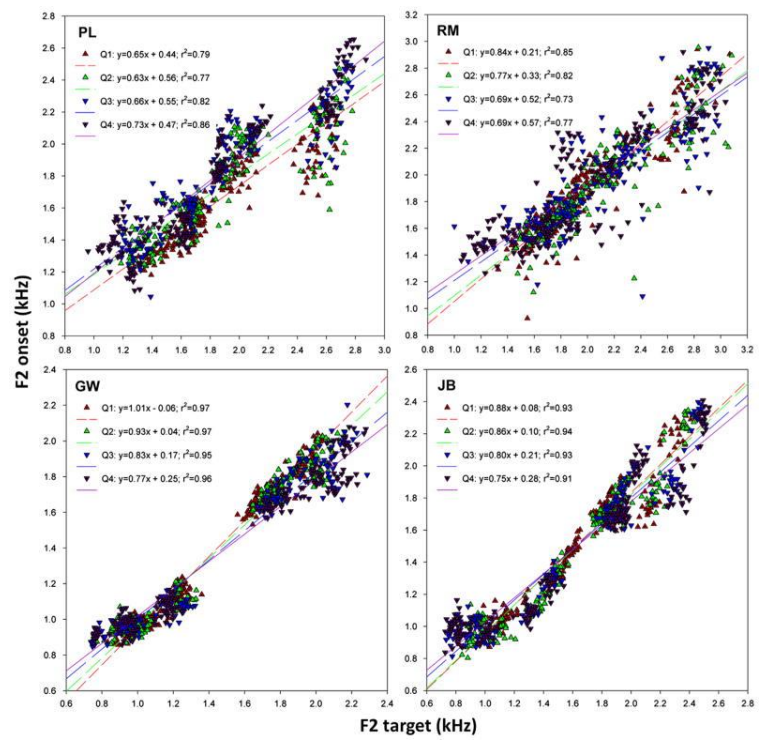

Locus equations plots for each speaker using all vowel contexts for each quartile of the vowel duration distribution.

Journal of Phonetics, Vol 41, No. 6 (November 2013): pg. 468-478. DOI. This article is @ Elsevier and permission has been granted for this version to appear in e-Publications@Marquette. Elsevier does not grant permission for this article to be further copied/distributed or hosted elsewhere without the express permission from Elsevier. 
NOT THE PUBLISHED VERSION; this is the author's final, peer-reviewed manuscript. The published version may be accessed by following the link in the citation at the bottom of the page.

All locus lines shown in Fig. 2 are associated with the relatively high $r^{2}$ values. These high proportions of explained variation are a common outcome for locus equations. There does not appear to be any systematic variation in $r^{2}$ values across quartiles.

\subsection{Locus lines by rate and speaker, between different pools and within vowel}

In prior work, (Weismer \& Berry, 2003) analyses of target-onset relations within vowel revealed relatively low $r^{2}$ values when compared with cross-vowel results reported by others (Sussman et al., 1998). In the current work, the potential influence of vowel pooling on the interpretation of locus equations is assessed by means of a direct comparison of various vowel pools as well as unpooled data (within vowel). Five different vowel pooling conditions were compared: (1) point vowels; (2) front vowels; (3) back vowels; (4) low vowels; and (5) high vowels.

Fig. 3 summarizes locus equation slopes by quartile for each speaker in the five different pooling conditions. Locus slopes obtained in the initial analysis, that included all vowel contexts are also shown in Fig. 3 for reference (filled circles, solid lines). The lines connecting data points within condition across quartiles are not intended to imply any expectation about linearity in the changing slope. These lines are simply there to make it easier to see the change in slope within pooling condition across quartiles.

Journal of Phonetics, Vol 41, No. 6 (November 2013): pg. 468-478. DOI. This article is @ Elsevier and permission has been granted for this version to appear in e-Publications@Marquette. Elsevier does not grant permission for this article to be further copied/distributed or hosted elsewhere without the express permission from Elsevier. 
Fig. 3
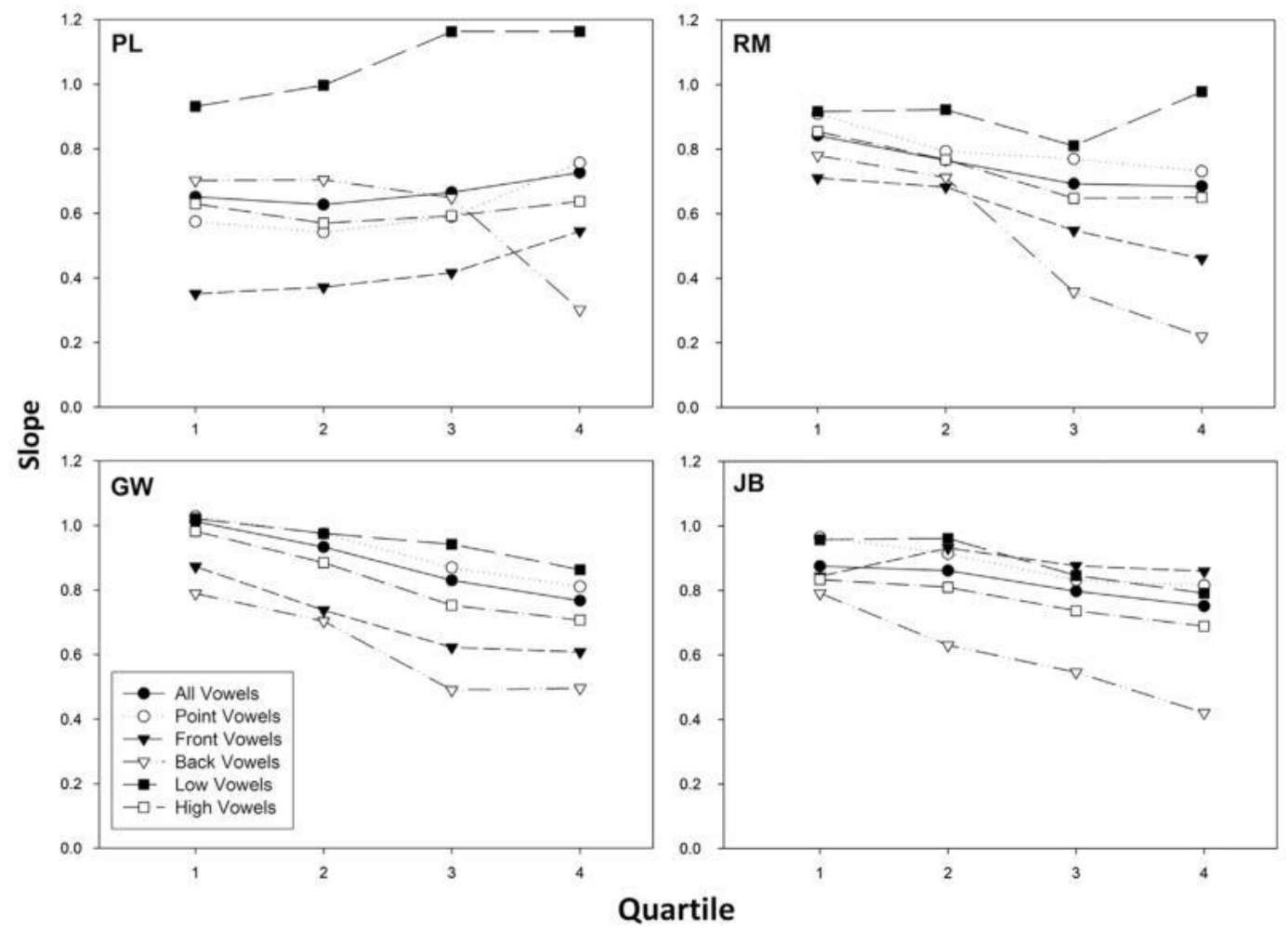

Locus slopes by quartile for five pooling conditions and the complete vowel-pooled condition for each speaker.

Results displayed in Fig. 3 suggest that for all speakers both the point vowel condition (open circles, dotted lines) and high vowel condition (open squares, dashed single-dotted lines) appear to reasonably approximate the results obtained in the "all vowel" analysis. In fact, for the three speakers that exhibited the expected reduction in locus slope with decreasing rate (RM, JB, and GW), systematic changes in slope between quartiles appear to recur in most pooling conditions, though the range, maximum, and minimum slopes differ somewhat between vowel pools. Exceptions include RM's low vowel condition (filled squares, large-dashed lines) and JB's front vowel condition (filled triangles, small-dashed lines), for which systematic changes in locus slope do not appear to correspond with rate change. For all speakers, the low vowel condition appears to produce the largest average slope values (across quartiles) with only modest change in slope between quartiles. In contrast, for all speakers except $\mathrm{PL}$, the back vowel condition (open triangles, dashed double-

Journal of Phonetics, Vol 41, No. 6 (November 2013): pg. 468-478. DOI. This article is (C) Elsevier and permission has been granted for this version to appear in e-Publications@Marquette. Elsevier does not grant permission for this article to be further copied/distributed or hosted elsewhere without the express permission from Elsevier. 
dotted lines) produces the lowest average slopes and the largest changes in slope between quartiles. The back vowel condition is also the only condition for which PL demonstrates a pattern of slope change across quartiles that follows a pattern consistent with locus equation expectations.

For within vowel analyses, locus lines were determined as described above, without vowel pooling. Given a locus line for each rate quartile within each of 10 vowel contexts, 40 locus lines characterize each speaker. Fig. 4 summarizes locus coefficients within vowel. Plots are arranged in columns by speaker. Legends in PL's plots identify the vowels for the upper row plots (front vowels) and lower row plots (central and back vowels) for all speakers.

Fig. 4
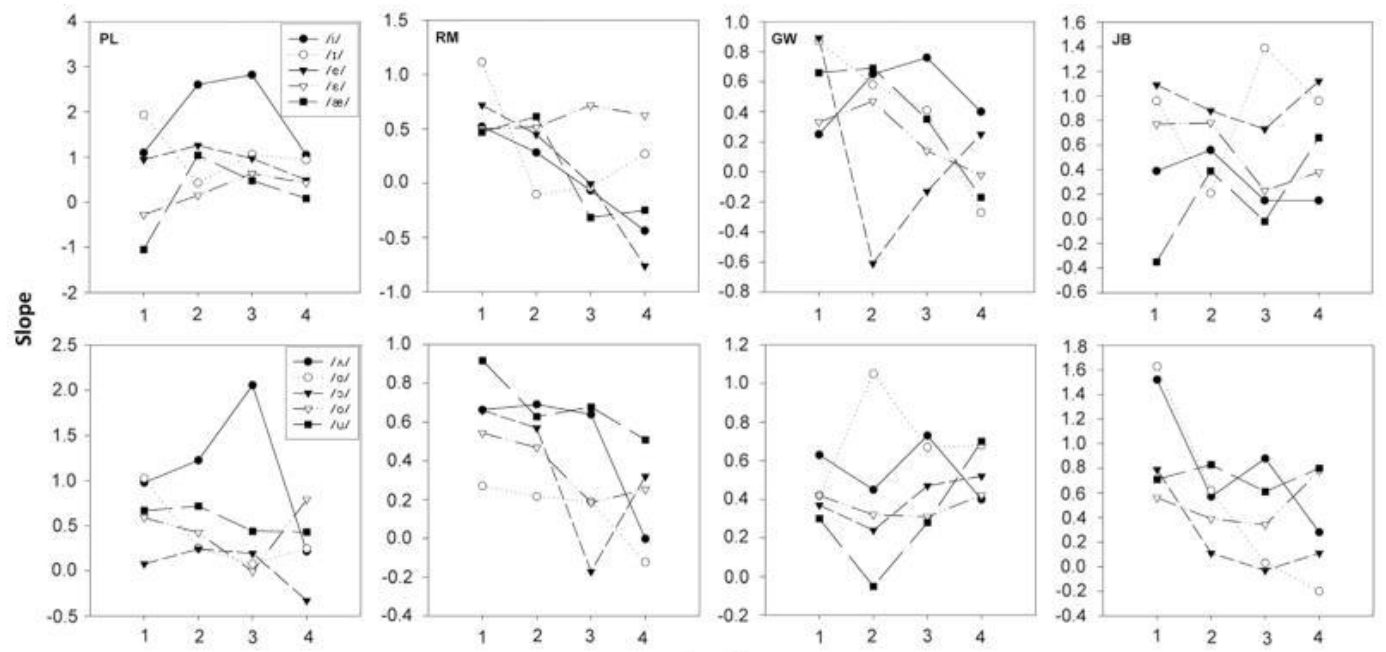

Summary of locus slope trends by rate quartile within vowel for all speakers.

When compared with Fig. 3, where the pooled data are summarized, a notable feature of these vowel-specific plots is the nearly complete absence of strict, unidirectional trends. Trends equivalent to those shown in Fig. 3 (i.e., slope inversely related to quartile number) are obtained in only one vowel context for each male speaker: JB's /C/ productions and GW'S /I/ productions, three contexts for RM (/i/, /e/, /d/), and for none of PL's vowels. Yet, less-rigorous criteria may be appropriate given the relatively smaller number of data points used to define the locus line coefficients in these plots,

Journal of Phonetics, Vol 41, No. 6 (November 2013): pg. 468-478. DOI. This article is (c) Elsevier and permission has been granted for this version to appear in e-Publications@Marquette. Elsevier does not grant permission for this article to be further copied/distributed or hosted elsewhere without the express permission from Elsevier. 
compared with the slopes summarized in Fig. 3. A partial trend, then, will be operationally defined as a unidirectional trend that would exist if one point representing a specific quartile was eliminated from the data for a specific vowel context. For example, looking at speaker JB's $/ \Lambda$ / data in the rightmost lower plot of Fig. 4, if data from the 3rd quartile (conversational slow speech) were eliminated from the analyses, a unidirectional trend of decreasing locus slope with increasing quartile number (decreasing rate) would be evident. Using this criterion, five more of speaker JB's vowels would follow trends deemed consistent with the pooled data $(/ \mathrm{i} /, \mathrm{l} / \mathrm{e}, \mathrm{/} / \mathrm{/}, \mathrm{J} / \mathrm{,} / \mathrm{o} /)$. Applying this criterion to his / $/$ data, a partial trend is visible in the opposite direction (slope rising with quartile number). For speaker GW, four more vowels may be deemed consistent with the pooled data using this less rigorous criterion $(/ \varepsilon /, / æ /, / d /, / o /)$. Four other vowels $(/ \mathrm{i} /, / \mathrm{e} /, \mathrm{\jmath} / \mathrm{,} / \mathrm{u} /)$, however, obtain trends in the opposite direction under the relaxed criterion. For speaker RM, four more vowels would also be consistent with the pooled data using this less rigorous criterion $(/ \Lambda /, / \nu /, / O /, / u /)$, but two vowels $(/ \varepsilon /, / I /)$ would obtain opposite trends. For $\mathrm{PL}$, seven vowels would be consistent with the pooled data (/i/, /e/, /æ/, /a/, /J/, /o/, /u/), but three words would obtain opposite trends $(/ \mathrm{i} /, / \varepsilon /, / \Lambda /)$. In general, using less rigorous criteria, about $1 / 2$ of the vowels produced by the male speakers and $3 / 4$ of the vowels produced by the female speakers might be deemed consistent with the results obtained for pooled data. The particular vowels for which these results are obtained do not appear to share any specific features (e.g., front vs. back, low vs. high) within or across speakers.

In summary, locus line coefficients from data pooled across vowel contexts tend to vary systematically with speaking rate. Slope values decrease as speaking rate slows and $y$-intercept values increase as speaking rate slows. These results were obtained for three out of four speakers producing 80 repetitions of each of 10 vowel contexts. Comparable analyses completed across various vowel pooling conditions revealed that locus slopes based on pooling point vowels or high vowels were most comparable to slopes calculated from 10 vowels. Pools of low vowels tended to produce the highest average slopes, and were least sensitive to rate change. Pools of back vowels tended to have the lowest average slopes, and were most sensitive to

Journal of Phonetics, Vol 41, No. 6 (November 2013): pg. 468-478. DOI. This article is (C) Elsevier and permission has been granted for this version to appear in e-Publications@Marquette. Elsevier does not grant permission for this article to be further copied/distributed or hosted elsewhere without the express permission from Elsevier. 
rate change. When comparable analyses were completed within vowel, results were far less consistent with pooled data. Using strict criteria, two speakers produced trends consistent with the pooled data for only a single vowel context, and one speaker produced consistent trends for three vowel contexts. If less rigorous standards are applied, about $1 / 2$ to 3/4 of each speaker's target vowel contexts may be deemed consistent with the pooled data.

\section{Discussion}

The purpose of this study was to evaluate effects of speaking rate on locus equation slopes and to explore the influences of crossvowel pooling on locus slope variation. To this end, acoustic data have been presented that reveal systematic variations in locus lines as a function of rate-induced coarticulatory changes for three of the four participants. The resulting unidirectional trends are obvious in data pooled across ten vowel contexts, but comparisons between different four vowel pooling conditions suggest that rate-induced variations in locus slope are affected by different vowel groupings with regard to the maximum and minimum slopes obtained and the sensitivity to rate variation. In particular, for all speakers, back vowels appear to be most sensitive to rate-induced locus slope variation while low vowels tend to be least sensitive. This may be a context-specific effect tied to the particular $\mathrm{V}_{1}(/ \mathrm{e} /)$ used in the target $\left(\mathrm{V}_{1} \mathrm{bV}_{2}\right)$ form in this study. Specifically, rate-induced locus slope sensitivity may be maximized within a context for which the tongue has to move a relatively long distance for the vowels used in a locus calculation and traverse the front-back dimension, since this may be more likely to result in variations in $\mathrm{F} 2$. This simple interpretation seems incompatible, however, with the lack of apparent sensitivity of low vowels (which would also include substantial front-back movement toward / $/$ and /a/ when coarticulated from /e/) and the somewhat surprising sensitivity of front vowels, which presumably would be affected minimally by coarticulation from /e/. Unfortunately, within vowel analyses do not seem to provide an obvious confirmation that certain vowel features may be particularly influential across speakers. Rateinduced locus slope variations that are obvious in pooled data are far less consistent when locus lines are fit within a particular vowel context, even when coarticulation is manipulated via a rather dense

Journal of Phonetics, Vol 41, No. 6 (November 2013): pg. 468-478. DOI. This article is (C) Elsevier and permission has been granted for this version to appear in e-Publications@Marquette. Elsevier does not grant permission for this article to be further copied/distributed or hosted elsewhere without the express permission from Elsevier. 
sampling of speaking rate variation. By implication, cross-vowel pooling does appear to exert an important influence on how the locus line serves as a general index of rate-induced coarticulation, even though it is clear that across-rate, within vowel analyses result in a substantial degree of spectral variation for both F2 onset and F2 target (see Fig. 1).

Much of the debate surrounding locus equations and coarticulation has focused on how to explain the linearity resulting from cross-vowel pooling (Fowler, 1994; Sussman et al., 1998; Lindblom \& Sussman, 2012). The influences of specific data pooling methods have never been evaluated. Fowler (1994) embraces the concept of uniform coarticulatory resistance to explain the systematic variation of locus equations in pooled-vowel analyses. In short, the extent to which a particular consonant gesture resists the influence of adjacent gestures is assumed to be invariant across vowels, and unique to the different places of stop articulation. Sussman et al. (1998) reject this idea, choosing instead to justify pooling by the very fact that order appears as a result of the process. In their words: "By displaying all variants of a given phonological category ... in one scatterplot, a dramatic orderliness, not evident at the level of single speech tokens, emerges for the first time in the form of tight clustering about the iso-stop regression line" (Sussman et al., 1998, p. 246). In effect, variability is required to evidence invariance.

Lindblom \& Sussman (2012) emphasize the idea that there is a spatio-temporal constancy of articulatory movement (e.g., unimodal velocity profiles). Instabilities in the locus slope-speaking rate relationship could be influenced by deviation from the symmetrical, unimodal velocity profiles that may be critical to the locus calculation, since the extreme slow speaking rates used in this study are known to be characterized by asymmetrical, multi-modal velocity profiles (Adams et al., 1993). In the current results, the possibility that rate violates the locus equation assumption of spatio-temporal constancy does not appear to be reflected in trends toward reduced $r^{2}$ values with decreasing rate. Any differences across quartiles are quite small and all locus lines tend to reflect the characteristically high $r^{2}$ values associated with locus equations. A more direct appraisal of this issue would require the analysis of rate-induced locus effects and corresponding velocity profile changes in synchronous kinematic data.

Journal of Phonetics, Vol 41, No. 6 (November 2013): pg. 468-478. DOI. This article is (c) Elsevier and permission has been granted for this version to appear in e-Publications@Marquette. Elsevier does not grant permission for this article to be further copied/distributed or hosted elsewhere without the express permission from Elsevier 
Such an extension of the current work may be justified since different forms of velocity profile may reflect different underlying control strategies for different ranges of speaking rate (Berry, 2011) that may require functionally distinct cortical networks, as has been argued with regard to rate-transformations associated with lower limb movements during walking (Vasudevan \& Bastian, 2010). Given the differential sensitivity of vowels to rate-induced compression and expansion, such categorically distinct changes in sensorimotor control across rates could have a complex relationship with vowel context.

Lindblom and Sussman (2012) suggest that spatio-temporal constancy reflects a consonant-level articulatory invariance, unaffected by vowel context. Broad and Clermont (2010) use similar consonantspecific transitions in their acoustic modeling work. Importantly, they emphasize that such an approach is descriptive and does not belie the underlying phonetic structures. Moreover, while the locus approach uses two time points along the transition (and therefore cannot be extended beyond a linear model), Broad and Clermont (2010) highlight the fact that real F2 transitions are often better characterized through exponential, rather than linear models, due to the more complex shape of transitions that have been sampled at all possible time frames. Moreover, the complexity of transition shapes may increase as speaking rate slows (Weismer \& Berry, 2003). So, while Broad and Clermont (2010) work may be interpreted as an independent confirmation of the practice of vowel pooling (see Lindblom \& Sussman, 2012), our perspective is that their consonant-specific transitional modeling method is operational and descriptive and does not offer a theoretical justification for cross-vowel pooling or a model that can simply be extended to rate-induced variation. Thus, while the spatio-temporal constancy of transitions may be sufficient for modeling, it does not appear to be an entirely accurate or necessary condition during human speech. With regard to the characterization of the coarticulatory effects of widely varying speaking rate, the inadequacy of simple scaling models has been demonstrated for formant transitions (Weismer \& Berry, 2003) and articulatory kinematics (Berry, 2011). Consequently, we feel justified in evaluating the practice of cross-vowel pooling. Are there vowel-specific articulatory influences on consonant production that could account for locus effects in pooled data?

Journal of Phonetics, Vol 41, No. 6 (November 2013): pg. 468-478. DOI. This article is (C) Elsevier and permission has been granted for this version to appear in e-Publications@Marquette. Elsevier does not grant permission for this article to be further copied/distributed or hosted elsewhere without the express permission from Elsevier. 
NOT THE PUBLISHED VERSION; this is the author's final, peer-reviewed manuscript. The published version may be accessed by following the link in the citation at the bottom of the page.

Berry (2004) performed a kinematic and modeling analysis of the release phase of $/ d /$ preceding six different vowels produced by a single male speaker using the X-ray microbeam system. He showed that release trajectories of a pellet roughly $10 \mathrm{~mm}$ back from the tongue tip showed systematic, vowel-specific effects. As one of these effects, Berry showed that the position of the pellet at the onset of voicing varied systematically with vowel identity. For example, when the speaker produced /dis/ the pellet was about $2 \mathrm{~mm}$ more anterior at vowel onset than it was at vowel onset for /dus/. According to speech acoustic theory, the F2 onset value for the /i/context should be higher than it is for the $/ \mathrm{u} /$ context, which is precisely what is found in locus equation studies in which the analyses are based on data pooled across vowels. When Berry used a Rothenberg-type model of breathstream dynamics (Müller \& Brown, 1980; Rothenberg, 1968), he was able to demonstrate that the time-dependent variations in crosssectional area at the expanding release constriction predicted the measured VOTs for / $d$ / quite well-and therefore also predicted voweldependent, F2 onset frequencies. The implication of this result is that variation in the time of occurrence of F2 onset, and therefore F2 onset frequency, can be accounted for by the vowel-specific effects on release kinematics.

The notion of vowel-specific effects is at odds with the basic locus equation model. Fig. 1 demonstrates clear effects of rate on both F2 onset and target values. Vowel target variability, however, is not accounted for in the basic locus model (Krull, 1988; Lindblom \& Sussman, 2012), since vowel target constancy is assumed. The only previous study of speaking rate effects on locus equations aimed to deal with this problem of vowel target variability by proposing an alternative method for deriving locus equations (Agwuele et al., 2008). Assessing locus equation effects across three nominal speaking rates, some of the outcomes are consistent with the current results. Agwuele et al. (2008) do not directly evaluate the influence of vowel pooling, but rather focus on the goal of separating coarticulatory effects associated with vowel reduction from other coarticulatory changes. The approach of Agwuele et al. (2008) might suggest that the current results reflect a mixture of effects of two distinct forms of coarticulation with different underlying origins. Yet, given the apparent complexity and idiosyncracy of rate-induced coarticulation, one might question the utility of a method derived from an underlying model that

Journal of Phonetics, Vol 41, No. 6 (November 2013): pg. 468-478. DOI. This article is (C) Elsevier and permission has been granted for this version to appear in e-Publications@Marquette. Elsevier does not grant permission for this article to be further copied/distributed or hosted elsewhere without the express permission from Elsevier. 
parcels rate transformation into only two forms of coarticulation. This concern is highlighted by the paucity of work that studies rate effects at both the articulatory and acoustic levels (cf., Mefferd \& Green, 2010) and the lack of articulatory modeling work aimed at generating hypothesis regarding the acoustic manifestations of different combinations and degrees of rate-induced articulatory transformation (Berry, 2011).

\section{Conclusions}

In the current work, acoustic data from three out of four talkers producing densely-sampled, large-scale variations in speaking rate are consistent with the notion that locus equation coefficients calculated from vowel-pooled data vary systematically with coarticulatory changes. Locus equation slope values and sensitivities are affected by the constituency of the pooled vowels analyzed and rate-induced locus slope variations within vowel are very unpredictable. Within vowel analyses based on the current linguistic context do not reveal clear speaker-general differences in the rate-induced coarticulatory transformations between vowels that may account for the effects of vowel pooling on locus line variation. Taken together, these results suggest that the practice of vowel pooling exerts a non-negligible influence on locus measures that is not clearly understood and must be accounted for if locus equations are to be interpreted as indices of coarticulation.

\section{Acknowledgments}

This work was supported by NIH R01 DC003723 and start-up funds from Marquette University. We would like to thank Kenneth de Jong and three anonymous reviewers for their constructive feedback on an earlier version of this manuscript. We would also like to thank Patricia Lyons and Rachel Myatt for their contributions to data acquisition.

\section{References}

Abbs $\mathrm{JH}$. The influence of the gamma motor system on the jaw movements during speech: A theoretical framework and some preliminary observations. Journal of Speech Language and Hearing Research. $1973 ; 16: 175-200$.

Journal of Phonetics, Vol 41, No. 6 (November 2013): pg. 468-478. DOI. This article is (c) Elsevier and permission has been granted for this version to appear in e-Publications@Marquette. Elsevier does not grant permission for this article to be further copied/distributed or hosted elsewhere without the express permission from Elsevier. 
NOT THE PUBLISHED VERSION; this is the author's final, peer-reviewed manuscript. The published version may be accessed by following the link in the citation at the bottom of the page.

Adams SG, Weismer G, Kent RD. Speaking rate and speech movement velocity profiles. Journal of Speech Language and Hearing Research. $1993 ; 36: 41-54$

Agwuele A, Sussman HM, Lindblom B. The effect of speaking rate on consonant vowel coarticulation. Phonetica. 2008;65(4):194-209.

Benguerel A, Cowan HA. Coarticulation of upper lip protrusion in French. Phonetica. 1974;30:41-55.

Berry J. Control of short-lag VOT for voiced English stops. Journal of the Acoustical Society of America. 2004;115(5):2465.

Berry J. Speaking rate effects of normal aspects of articulation: outcomes and issues. Perspectives on Speech Science and Orofacial Disorders. 2011;21(1):15-26.

Boyce SE, Krakow RA, Bell-Berti F, Gelfer CE. Converging sources of evidence for dissecting articulatory movements into core gestures. Journal of Phonetics. 1990;18:173-188.

Broad DJ, Clermont F. Target-locus scaling methods for modeling families of formant transitions. Journal of Phonetics. 2010;38(3):337-359.

Byrd D, Tan CC. Saying consonant clusters quickly. Journal of Phonetics. $1996 ; 24: 263-282$.

Chang SE, Ohde RN, Conture EG. Coarticulation and formant transition rate in young children who stutter. Journal of Speech Language and Hearing Research. 2002;45:676-688.

Chennoukh S, Carré R, Lindblom B. Locus equations in light of articulatory modeling. Journal of the Acoustical Society of America. 1997; 102:2380-2389.

Crystal TH, House AS. Segmental durations in connected speech signals: preliminary results. Journal of the Acoustical Society of America. 1982;72(3):705-716.

Crystal TH, House AS. A note on the variability of timing control. Journal of Speech Language and Hearing Research. 1988a;31:497-502.

Crystal TH, House AS. Segmental durations in connected-speech signals: Current results. Journal of the Acoustical Society of America. $1988 b ; 83: 1553-1573$.

Engstrand O. Articulatory correlates of stress and speaking rate in Swedish vcv utterances. Journal of the Acoustical Society of America. 1988;83:1863-1875.

Fant CGM. Speech sounds and features. Cambridge, USA: MIT Press; 1973.

Flege JE. Effects of speaking rate on tongue position and velocity of movement in vowel production. Journal of the Acoustical Society of America. 1988;84:901-916.

Fourakis M. Tempo, stress, and vowel reduction in American English. Journal of the Acoustical Society of America. 1991;90:1816-1827.

Journal of Phonetics, Vol 41, No. 6 (November 2013): pg. 468-478. DOI. This article is (c) Elsevier and permission has been granted for this version to appear in e-Publications@Marquette. Elsevier does not grant permission for this article to be further copied/distributed or hosted elsewhere without the express permission from Elsevier 
NOT THE PUBLISHED VERSION; this is the author's final, peer-reviewed manuscript. The published version may be

accessed by following the link in the citation at the bottom of the page.

Fowler CA. Invariants, specifiers and cues: An investigation of locus equations as information for place of articulation. Perception \& Psychophysics. 1994;55:597-610.

Fowler CA. The orderly output constraint is not wearing any clothes. Behavioral and Brain Sciences. 1998;21:265-266.

Fuchs S, Perrier P, Hartinger M. A critical evaluation of gestural stiffness estimations in speech production based on a linear second-order model. Journal of Speech Language and Hearing Research. 2011;54(4):1067.

Gay T. Effect of speaking rate on diphthong formant movements. Journal of the Acoustical Society of America. 1968;44:1570-1573.

Gay T. Effect of speaking rate on vowel formant movements. Journal of the Acoustical Society of America. 1978;63:223-230.

Gay T. Mechanisms in the control of speech rate. Phonetica. 1981;38:148151.

Gay T, Hirose H. Effect of speaking rate on labial consonant production. Phonetica. 1973;27:44-56.

Gay T, Ushijima T, Hirose H, Cooper FS. Effect of speaking rate on labial consonant-vowel articulation. Journal of Phonetics. 1974;2:47-63.

Gibson T, Ohde RN. F2 locus equations: phonetic descriptors of coarticulation in 17-to-22-month-old children. Journal of Speech Language and Hearing Research. 2007;50:97-108.

Goozee J, Stephenson D, Murdoch B, Darnell R, Lapointe L. Lingual kinematic strategies used to increase speech rate: comparison between younger and older adults. Clinical Linguistics \& Phonetics. 2005;19(4):319-334.

Hertrich I, Ackermann H. Coarticulation in slow speech: durational and spectral analysis. Language and Speech. 1995;38:159-187.

Hertrich I, Ackermann H. Lip-jaw and tongue-jaw coordination during ratecontrolled syllable repetitions. Journal of the Acoustical Society of America. 2000;107:2236-2247.

Hillenbrand J, Getty LA, Clark MJ, Wheeler K. Acoustic characteristics of American English vowels. Journal of the Acoustical Society of America. 1995; 97:3099-3111.

Iskarous $\mathrm{K}$, Fowler CA, Whalen DH. Locus equations are an expression of articulator synergy. Journal of the Acoustical Society of America. 2010;128:2021-2032.

Kelso JAS, Vatikiotis-Bateson E, Saltzman EL, Kay B. A qualitative dynamic analysis of reiterant speech production: phase portraits, kinematics, and dynamic modeling. Journal of the Acoustical Society of America. $1985 ; 77: 266-280$.

Kelso JA, Saltzman EL, Tuller B. The dynamical perspective on speech production: Data and theory. Journal of Phonetics. 1986;14(1):29-59.

Journal of Phonetics, Vol 41, No. 6 (November 2013): pg. 468-478. DOI. This article is (C) Elsevier and permission has been granted for this version to appear in e-Publications@Marquette. Elsevier does not grant permission for this article to be further copied/distributed or hosted elsewhere without the express permission from Elsevier. 
Kent RD, Moll KL. Cinefluorographic analyses of selected lingual consonants. Journal of Speech Language and Hearing Research. 1972;15:453-473.

Kuehn DP, Moll KL. A cinderadiographic study of vc and cV articulatory velocities. Journal of Phonetics. 1976;4:303-320.

Krull D. Acoustic properties as predictors of perceptual responses: A study of Swedish voiced stops. PERILUS. 1988;X:87-101.

Lindblom B. Spectrographic study of vowel reduction. Journal of the Acoustical Society of America. 1963;35:1773-1781.

Lindblom B. Explaining phonetic variation: A sketch of the H\&H Theory. In: Hardcastle W, Marchal A, editors. Speech production and speech modeling. Dordrecht: Kluwer; 1990. pp. 403-439.

Lindblom B, Sussman HM. Proceedings FONETIK. 8-11. Dept. of Linguistics, Stockholm University; 2004. Articulatory and acoustic bases of locus equations; pp. 8-11.pp. 8-11.

Lindblom B, Agwuele A, Sussman HM, Cortes EE. The effect of emphatic stress on consonant vowel coarticulation. Journal of the Acoustical Society of America. 2007;121:3802-3813.

Lindblom B, Sussman HM, Agwuele A. A duration-dependent account of coarticulation for hyper-and hypoarticulation. Phonetica. 2009;66(3):188-195.

Lindblom B, Sussman HM. Dissecting coarticulation: How locus equations happen. Journal of Phonetics. 2012;40(1):1-19.

Löfqvist $A$. Interarticulator phasing, locus equations, and degree of coarticulation. Journal of the Acoustical Society of America. 1999;106(4):2022-2030.

Mattingly IG. Why did coarticulation evolve. Behavioral and Brain Sciences. $1998 ; 21: 275-276$.

McClean M. Patterns of orofacial movement velocity across variations in speech rate. Journal of Speech Language and Hearing Research. 2000;43:205-216.

McClean M, Tasko S. Association of orofacial muscle activity and movement during changes in speech rate and intensity. Journal of Speech Language and Hearing Research. 2003;46(6):1387-1400.

Mefferd AS, Green JR. Articulatory-to-acoustic relations in response to speaking rate and loudness manipulations. Journal of Speech Language and Hearing Research. 2010;53(5):1206-1219.

Milenkovic P. TF32: Time-frequency analysis for 32-bit Windows [Computer Software] Madison: Milenkovic; 1998.

Modaressi G, Sussman HM, Lindblom B, Burlingame E. Locus equation encoding of stop place: revisiting the voicing/VOT issue. Journal of Phonetics. 2005;33:101-113.

Journal of Phonetics, Vol 41, No. 6 (November 2013): pg. 468-478. DOI. This article is (C) Elsevier and permission has been granted for this version to appear in e-Publications@Marquette. Elsevier does not grant permission for this article to be further copied/distributed or hosted elsewhere without the express permission from Elsevier. 
NOT THE PUBLISHED VERSION; this is the author's final, peer-reviewed manuscript. The published version may be

accessed by following the link in the citation at the bottom of the page.

Moon SJ, Lindblom B. Interaction between duration, context, and speaking style in English stressed vowels. Journal of the Acoustical Society of America. 1994;96(1):40-55.

Morrison HM. The locus equation as an index of coarticulation in syllable produced by speakers with profound hearing loss. Clinical Linguistics \& Phonetics. 2008;22(9):726-740.

Morrison HM. Coarticulation in early vocalizations of children with hearing loss: A locus perspective. Clinical Linguistics \& Phonetics. 2012;26(3):288-309.

Müller EM, Brown WS. Variations in the supraglottal air pressure waveform and their articulatory interpretation. In: Lass, editor. Speech and language: advances in basic research and practice. Vol. 4. New York: Academic Press, Inc; 1980. pp. 318-389.

Munhall K, Löfqvist A. Gestural aggregation in speech: laryngeal gestures. Journal of Phonetics. 1992;20:93-110.

Munhall KG, Ostry DJ, Parush A. Characteristics of velocity profiles of speech movements. Journal of Experimental Psychology: Human Perception and Performance. 1985;11(4):457-474.

Niimi MNS. Speaking rate and its components in dysarthric speakers. Clinical Linguistics \& Phonetics. 2001;15(4):309-317.

Nishio M, Niimi MNS. Comparison of speaking rate, articulation rate and alternating motion rate in dysarthric speakers. Folia Phoniatrica et Logopaedica. 2006;58(2):114-131.

Ostry DJ, Keller E, Parush A. Similarities in the control of the speech articulators and the limbs: Kinematics of tongue dorsum movement in speech. Journal of Experimental Psychology: Human Perception and Performance. 1983;9(4):622-636.

Ostry DJ, Munhall KG. Control of rate and duration of speech movements. Journal of the Acoustical Society of America. 1985;77:640-648.

Ostry DJ, Cooke JD, Munhall KG. Velocity curves of human arm and speech movements. Experimental Brain Research. 1987;68(1):37-46.

Perkell JS, Zandipour M, Matthies ML, Lane H. Economy of effort in different speaking conditions. I: A preliminary study of intersubject differences and modeling issues. Journal of the Acoustical Society of America. 2002;112(4):1627-1641.

Pitermann M. Effect of speaking rate and contrastive stress on formant dynamics and vowel perception. Journal of the Acoustical Society of America. 2000;107:3425-3437.

Plamondon R. A kinematic theory of rapid human movements. Biological Cybernetics. 1995;72(4):309-320.

Rosen KM, Folker JE, Murdoch BE, Vogel AP, Cahill LM, Delatycki MB, et al. Measures of spectral change and their application to habitual, slow,

Journal of Phonetics, Vol 41, No. 6 (November 2013): pg. 468-478. DOI. This article is (C) Elsevier and permission has been granted for this version to appear in e-Publications@Marquette. Elsevier does not grant permission for this article to be further copied/distributed or hosted elsewhere without the express permission from Elsevier 
NOT THE PUBLISHED VERSION; this is the author's final, peer-reviewed manuscript. The published version may be accessed by following the link in the citation at the bottom of the page.

and clear speaking modes. International Journal of Speech-Language Pathology. 2011;13(2):165-173.

Rothenberg $M$. The breath-stream dynamics of simple-released plosive production. Bibliotheca Phonetica. 1968;6:1-117.

Saltzman E, Byrd D. Task-dynamics of gestural timing: Phase windows and multifrequency rhythms. Human Movement Science. 2000;19(4):499526.

Shaiman S. Kinematics of compensatory vowel shortening: the effect of speaking rate and coda composition on intra- and inter-articulatory timing. Journal of Phonetics. 2001;29:89-107.

Shaiman S. Articulatory control of vowel length for contiguous jaw cycles: the effects of speaking rate and phonetic context. J Speech Lang Hear Res. 2002;45(4):663-675.

Shaiman S, Adams SG, Kimelman MDZ. Velocity profiles of lip protrusion across changes in speaking rate. Journal of Speech Language and Hearing Research. 1997;40(1):144-158.

Shaiman S, Adams SG, Kimelman MDZ. Timing relationships of the upper lip and jaw across changes in speaking rate. J Phonetics. 1995;23:119128.

Simko J, Cummins F. Embodied task dynamics. Psychological Review. $2010 ; 117(4): 1229-1246$.

Stevens KN, House AS. Perturbation of vowel articulations by consonantal context: An acoustical study. Journal of Speech Language and Hearing Research. 1963;6(2):111-128.

Sussman HM, Hoemeke K, McCaffrey HA. Locus equations as an index of coarticulation for place of articulation distinctions in children. Journal of Speech Language and Hearing Research. 1992;35:769-781.

Sussman HM, Minifie FD, Buder EH, Stoel-Gammon C, Smith J. Consonantvowel interdependencies in babbling and early words: Preliminary examination of a locus equation approach. Journal of Speech Language and Hearing Research. 1996;39:424-433.

Sussman HM, Fruchter D, Hilbert J, Sirosh J. Linear correlates in the speech signal: The orderly output constraint. Behavioral and Brain Sciences. 1998;21:241-299.

Tabain M. Coarticulation in CV syllables: a comparison of locus equation and EPG data. Journal of Phonetics. 2000;28:137-159.

Tabain M. Voiceless consonants and locus equations: A comparison with electropalatographic data on coarticulation. Phonetica. 2002;59(1):2037.

Tasko S, McClean M. Variations in articulatory movement with changes in speech task. Journal of Speech Language and Hearing Research. 2004;47(1):85-100.

Journal of Phonetics, Vol 41, No. 6 (November 2013): pg. 468-478. DOI. This article is (C) Elsevier and permission has been granted for this version to appear in e-Publications@Marquette. Elsevier does not grant permission for this article to be further copied/distributed or hosted elsewhere without the express permission from Elsevier. 
NOT THE PUBLISHED VERSION; this is the author's final, peer-reviewed manuscript. The published version may be accessed by following the link in the citation at the bottom of the page.

Tjaden K, Weismer G. Speaking-rate-induced variability in F2 trajectories. Journal of Speech Language and Hearing Research. 1998;41:976-989.

Tsao YC, Weismer G. Interspeaker variation in habitual speaking rate: Evidence for a neuromuscular component. Journal of Speech Language and Hearing Research. 1997;40(4):858-866.

Tsao YC, Weismer G, Iqbal K. Interspeaker variation in habitual speaking rate: Additional evidence. Journal of Speech Language and Hearing Research. 2006a;49(5):1156-1164.

Tsao YC, Weismer G, Iqbal K. The effect of intertalker speech rate variation on acoustic vowel space. Journal of the Acoustical Society of America. 2006b;119:1074-1082.

Vasudevan EV, Bastian AJ. Split-belt treadmill adaptation shows different functional networks for fast and slow human walking. Journal of Neurophysiology. 2010;103(1):183-191.

Weismer G, Berry J. Effects of speaking rate on second formant trajectories of selected vocalic nuclei. Journal of the Acoustical Society of America. $2003 ; 113(6): 3362-3378$.

Journal of Phonetics, Vol 41, No. 6 (November 2013): pg. 468-478. DOI. This article is @ Elsevier and permission has been granted for this version to appear in e-Publications@Marquette. Elsevier does not grant permission for this article to be further copied/distributed or hosted elsewhere without the express permission from Elsevier. 